\title{
Guillain-Barré Syndrome Outbreak in Peru 2019 Associated With Campylobacter jejuni Infection
}

Ana P. Ramos, MD, Sonja E. Leonhard, MD, Susan K. Halstead, PhD, Mireya A. Cuba, MD, Carlos C. Castañeda, MD, Jose A. Dioses, MD, Martin A. Tipismana, MD, Jesus T. Abanto, MD, Alejandro Llanos, MD, PhD, Dawn Gourlay, BSc, MSc, Max Grogl, PhD, Mariana Ramos, MD, Jesus D. Rojas, BSc, Rina Meza, BSc, Daniela Puiu, MS, Rachel M. Sherman, BS, MSE, Steven L. Salzberg, PhD,

Patricia J. Simner, PhD, Hugh J. Willison, MBBS, Bart C. Jacobs, MD, David R. Cornblath, MD,

Hugo F. Umeres, MD,* and Carlos A. Pardo, MD*

Neurol Neuroimmunol Neuroinflamm 2021;8:e952. doi:10.1212/NXI.0000000000000952

\section{Abstract}

\section{Objective}

To identify the clinical phenotypes and infectious triggers in the 2019 Peruvian Guillain-Barré syndrome (GBS) outbreak.

\section{Methods}

We prospectively collected clinical and neurophysiologic data of patients with GBS admitted to a tertiary hospital in Lima, Peru, between May and August 2019. Molecular, immunologic, and microbiological methods were used to identify causative infectious agents. Sera from 41 controls were compared with cases for antibodies to Campylobacter jejuni and gangliosides. Genomic analysis was performed on $4 \mathrm{C}$ jejuni isolates.

\section{Results}

The 49 included patients had a median age of 44 years (interquartile range [IQR] 30-54 years), and 28 (57\%) were male. Thirty-two (65\%) had symptoms of a preceding infection: 24 (49\%) diarrhea and 13 (27\%) upper respiratory tract infection. The median time between infectious to neurologic symptoms was 3 days (IQR 2-9 days). Eighty percent had a pure motor form of GBS, 21 (43\%) had the axonal electrophysiologic subtype, and 18\% the demyelinating subtype. Evidence of recent $C$ jejuni infection was found in 28/43 (65\%). No evidence of recent arbovirus infection was found. Twenty-three cases vs 11 controls (OR 3.3, confidence interval [CI] 95\% 1.2-9.2, $p<0.01)$ had IgM and/or IgA antibodies against C jejuni. Anti-GM1: phosphatidylserine and/or anti-GT1a:GM1 heteromeric complex antibodies were strongly positive in cases (92.9\% sensitivity and $68.3 \%$ specificity). Genomic analysis showed that the $C$ jejuni strains were closely related and had the Asn51 polymorphism at cstII gene.

\section{Conclusions}

Our study indicates that the 2019 Peruvian GBS outbreak was associated with $C$ jejuni infection and that the $C$ jejuni strains linked to GBS circulate widely in different parts of the world.

\author{
Correspondence \\ Dr. Ramos \\ ana.ramos.t@upch.pe
}




\section{Glossary}

CHIKV = chikungunya virus; DENV = dengue virus; EGRIS = Erasmus GBS Respiratory Insufficiency Score; GBS = GuillainBarré syndrome; GBSDS = Guillain-Barré syndrome Disability Score; $\mathbf{H C}=$ healthy control; $\mathbf{H C H}=$ Hospital Cayetano Heredia; IQR = interquartile range; $\mathbf{L O S}$ = lipo-oligosaccharide; $\mathbf{m E G O S}=$ modified Erasmus GBS Outcome Score; $\mathbf{M R C}=$ Medical Research Council; $\mathbf{m R S}$ = modified Rankin Scale; NCBI = National Center for Biotechnology Information; NCS = nerve conduction study; PS = phosphatidylserine; $\mathbf{R O C}$ = receiver operating characteristic; $\mathbf{S T}=$ sequence type; ZIKV = Zika virus.

Guillain-Barré syndrome (GBS) is an immune-mediated disorder frequently triggered by infections, characterized by an acute flaccid paralysis, accompanied by sensory symptoms and cranial nerve deficits. ${ }^{1}$ In recent years, several outbreaks of GBS have been observed globally, including the large outbreaks in Latin America during the Zika virus (ZIKV) epidemic, $^{2-4}$ and the possibility of an association between severe acute respiratory syndrome coronavirus 2 infection and GBS has been raised. ${ }^{5}$ As the ZIKV epidemic transitioned to an endemic phase in the Americas in 2017, 2 major outbreaks of GBS occurred in Peru in 2018 and 2019. The number of reported GBS cases increased from 59 in 2017 (incidence: $0.19 / 100,000$ ) to 262 in 2018 (incidence: $0.81 / 100,000$ ) and 1,120 in 2019 (incidence: 3.44/100,000). ${ }^{6}$ During these outbreaks, the increases in GBS cases were also reported in areas where there is no potential arboviral transmission, such as the highlands of Peru. The outbreaks had a seasonal pattern with the major peaks occurring between April and July in both years (figure $1 \mathrm{~A}$ ) ${ }^{6,7} \mathrm{We}$ investigated the causality of these outbreaks, by performing an observational clinical cohort study of adult patients with GBS evaluated at a tertiary university hospital in Lima during the 2019 outbreak.

\section{Methods}

\section{Study Population and Design}

We prospectively evaluated the clinical and laboratory features of patients suspected of GBS at the Hospital Cayetano Heredia $(\mathrm{HCH})$, a university-based tertiary care hospital in Lima, Peru, during the 2019 GBS outbreak (May-August) in Peru. We included all patients who were evaluated by a neurologist and fulfilled the Brighton Collaboration Working Group criteria for diagnosis of GBS with a classification level 1,2 , or $3 .{ }^{8}$ Included patients underwent neurologic evaluation during the acute and convalescent phase of their illness and were followed up to 6 months after discharge. Patients with alternative diagnoses or insufficient data were excluded. Blood, CSF, respiratory, and stool samples were obtained during the acute phase as part of the standard of care to identify potential infectious etiologies. Nerve conduction studies (NCSs) and EMG were performed and classified according to the criteria of Hadden et al. ${ }^{9,10}$ The clinical and laboratory information was documented using standardized questionnaires of the Neuroviruses Emerging in the Americas Study forms adapted from the International GBS Outcome Study. ${ }^{3,11}$
The onset of GBS and disease nadir were defined as the first day of neurologic symptoms and the most severe clinical weakness, respectively. Pure motor GBS was defined as limb weakness in the absence of sensory deficits at neurologic examination, and sensorimotor GBS was defined as presence of both limb weakness and sensory deficits. Limb muscle strength was evaluated using the Medical Research Council (MRC) sum score. ${ }^{12}$ Severity was assessed according to the modified Rankin Scale (mRS), ${ }^{13}$ the GBS Disability Score (GBSDS), ${ }^{14}$ the modified Erasmus GBS Outcome Score (mEGOS), ${ }^{15}$ and the Erasmus GBS Respiratory Insufficiency Score at admission (EGRIS). ${ }^{16}$

\section{Laboratory Testing}

Hematologic and comprehensive metabolic assessments, including among others sodium and potassium levels, liver and kidney function tests, and HIV serology, were performed in all patients at admission. For the investigation of infectious agents, blood, CSF, oropharyngeal swabs, and stool samples were tested at the Naval Medical Research Unit 6 in Lima, Peru. Blood samples were assessed for arboviral infections including ZIKV, dengue virus (DENV), and chikungunya virus (CHIKV) using quantitative real time-PCR. ${ }^{17}$ Oropharyngeal swabs were tested for 20 respiratory pathogens using a multiplexed PCR assay (BioFire Diagnostics, Salt Lake City, UT). Stool swabs in Cary Blair medium were analyzed using a multiplexed PCR assay for gastrointestinal pathogens (BioFire Diagnostics), which included 22 pathogens associated with gastroenteritis, such as Campylobacter species (jejuni, coli, and upsaliensis), and Escherichia coli. Stool samples were cultured for identification and characterization of $E$ coli and $C$ jejuni. ${ }^{18}$ Positive culture samples were further characterized using multiplexed PCR assays for identification of $C$ jejuni ${ }^{19}$ and Penner types. ${ }^{19,20} C$ jejuni isolates from stool cultures were sequenced using next-generation sequencing techniques, and the genomic assemblies underwent genomic and phylogenetic analysis based on the hypervariable lipo-oligosaccharide (LOS) region. Phylogenetic analysis was based on $83 C$ jejuni genome assemblies from the National Center for Biotechnology Information (NCBI), which included all 16 genomes reported to be associated with GBS in the NCBI metadata and 67 additional genomes selected to represent a wide range of the collection locations, dates, and studies available (appendix e- 1 , links.lww.com/NXI/A403). These 83 genomes, the $C$ jejuni reference genome (NCTC11168), ${ }^{21,22}$ and the 4 genomes of 4 $C$ jejuni isolates assembled from the present study were used to construct a phylogenic tree from the sequence of the 

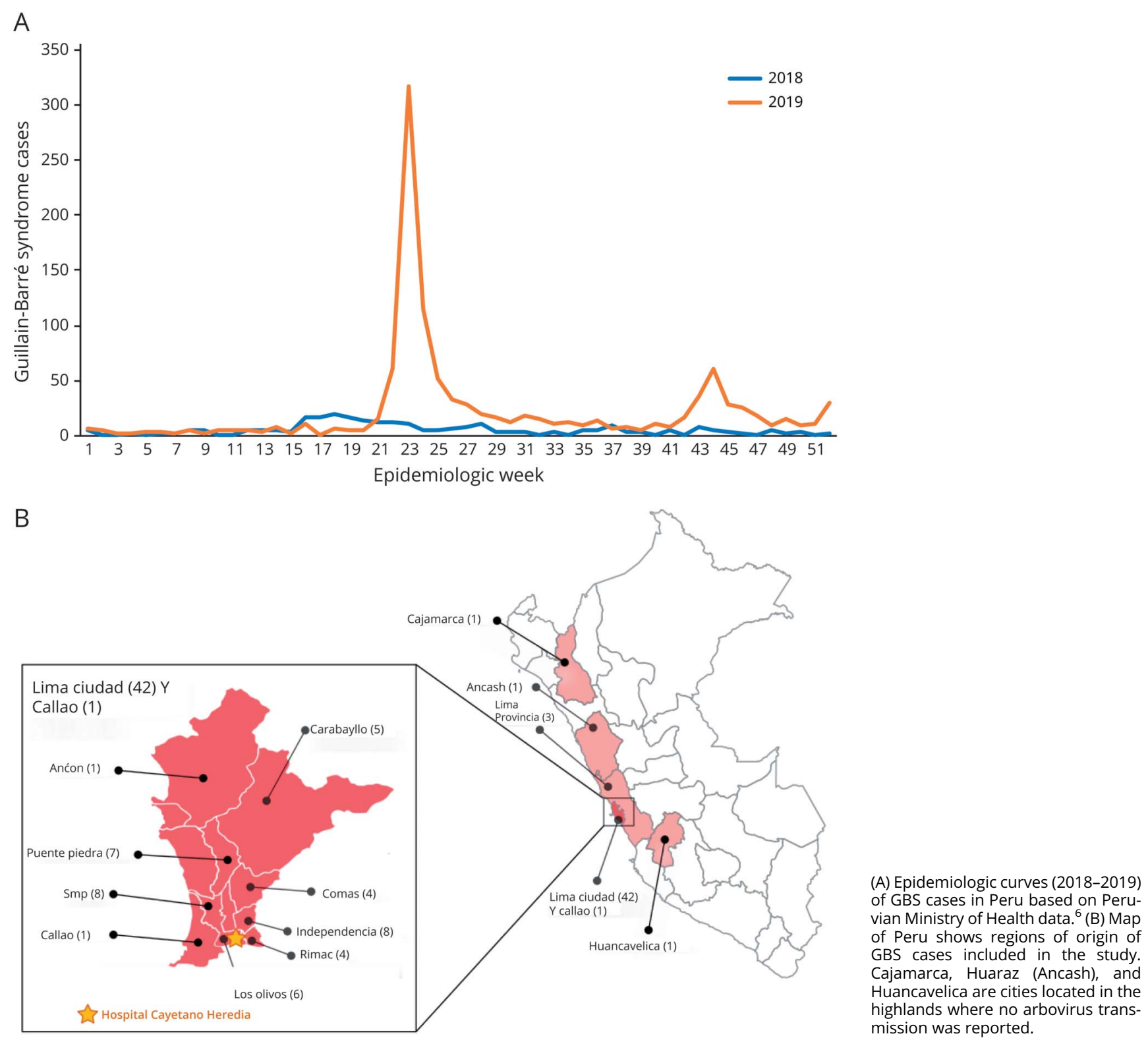

hypervariable LOS biosynthesis gene locus using the Nextstrain-Augur pipeline. ${ }^{23}$

To evaluate the association between $C$ jejuni infection and GBS, serum samples from 42 GBS cases were compared with serum samples of 41 controls for the presence of anti-C jejuni IgA, IgM, and IgG antibodies by ELISA following a casecontrol methodology. ${ }^{24}$ Control samples were obtained from subjects from the same or neighboring households of the patients with GBS. The controls were evaluated by a neurologist to exclude a history of weakness within the previous year and to document normal neurologic status. The presence of anti-C jejuni antibodies was expressed as a ratio of optical density between a test sample and the cutoff serum sample. A ratio > 1.0 for IgM or IgA was considered evidence of a recent
$C$ jejuni infection. Concomitant $C$ jejuni infection was defined as a positive Campylobacter PCR in a stool sample or by stool culture.

Case-control methodology was also used to study antiganglioside immunity using a multiplexed array panel to identify specific antiganglioside IgG antibodies. Patient and control sera were screened on microarrays. ${ }^{25}$ Glycolipid microarrays consisted of a panel of 16 single glycolipids, the majority of which are gangliosides (GM1, GM2, phosphatidylserine [PS], GM4, GA1, GD1a, GD1b, GT1a, GT1b, GQ1b, GD3, SGPG, LM1, GalNAc-GD1a, GalC, and sulfatide) and 120 heteromeric $1: 1(\mathrm{v}: \mathrm{v})$ complexes printed in duplicate. The presence of antiglycolipid antibodies was determined using human IgG isotype-specific, fluorescent- 
conjugated secondary antibodies, and its intensity was measured on a scale of 0-65,535 using a Genepix 4300A (Molecular Devices, San Jose, CA) microarray scanner. Antibody intensity values were reported as the average of duplicate median fluorescent intensity values per sample. Results were graphically displayed as heat maps using Pearson correlation hierarchical clustering ( $\mathrm{MeV}$ software). The optimal cutoff value for antiglycolipid IgG antibodies, above baseline levels, was calculated from receiver operating characteristic (ROC) curves using Youden index.

\section{Statistical Analysis}

The clinical and laboratory findings were described using absolute and relative frequencies. Median and interquartile ranges (IQRs) were reported for quantitative variables. The $\chi^{2}$ or Fisher exact test, OR, and $95 \%$ CIs were used to determine differences between the groups. A $p$ value $<0.05$ was considered significant. Area under the curve was calculated for each antiglycolipid antibody combination in ROC analysis. Statistical analyses were performed using Stata software, V15.0 (College-Station, TX).

\section{Ethical Considerations}

This study was reviewed and approved by the $\mathrm{HCH}$ Institutional Review Board. All patients (or relatives when patients were incapacitated) and healthy controls (HCs) provided written informed consent.

\section{Data Availability}

All data reported within the article are available anonymized on reasonable request by qualified investigators.

\section{Results}

\section{Clinical Features}

Fifty-nine patients suspected of GBS were seen between May and August 2019. Ten were excluded: 8 had insufficient data due to transfer to other hospitals during the outbreak, 1 patient had a recent infection with HIV, syphilis and tuberculosis, and 1 patient had only cranial nerve involvement. Of the 49 included patients, 43 were from Lima city and 6 from Northern area and highlands of Peru (figure 1B). The demographic and clinical characteristics of the 49 patients are described in table 1 . All patients fulfilled Brighton criteria level 1 (84\%) or level 2 (16\%). The median age was 44 years (IQR 30-54 years), and $28(57 \%)$ were male. Thirty-two patients (65\%) had symptoms of an infection 6 weeks preceding the onset of GBS: 24 (49\%) diarrhea and 13 (27\%) upper respiratory tract symptoms, and 2 patients $(4 \%)$ received an influenza vaccine. The median time from onset of infectious to neurologic symptoms was 3 days (IQR 2-9 days), and the time from onset of neurologic symptoms to nadir was 6 days (IQR 3-7 days). At admission, all patients reported limb weakness. Quadriparesis evolving in less than 24 hours from neurologic symptom onset was observed in 5 patients (10\%). The median GBSDS at admission was 4 (IQR 3-4), and EGRIS was 3 (IQR 2-4). Fifteen patients $(31 \%)$ had cranial neuropathy, with the facial nerve most commonly involved. The median MRC sum score was 42 (IQR 26-50). Most patients (80\%) were classified clinically as pure motor GBS. Neurologic examination, treatment, and outcome at nadir and at 6-month follow-up are detailed in table e-1 (links.lww.com/NXI/A406).

NCSs/EMG studies were performed in all patients at a median of 16 days after onset of neurologic symptoms (IQR 10-23 days). Twenty-one patients (43\%) had axonal neuropathy (acute motor axonal neuropathy), 9 (18\%) demyelinating neuropathy (acute inflammatory demyelinating polyneuropathy), 8 (16\%) equivocal, 5 (10\%) inexcitable, and $6(12 \%)$ had normal studies.

Forty-seven patients (96\%) received treatment with IVIg (51\%), plasmapheresis $(18 \%)$, or both $(27 \%)$. The standard treatment was 5 sessions of plasmapheresis or $0.4 \mathrm{mg} / \mathrm{kg} /$ $\mathrm{d}$ IVIg for 5 days. IVIg treatment was stopped in 1 patient who developed angioedema during their second session and who died before starting plasmapheresis. Two patients did not receive treatment, 1 because of lack of treatment availability on admission and 1 due to initial misdiagnosis. Both patients improved without treatment. Thirteen patients (27\%) were admitted to the intensive care unit, 12 (24\%) required ventilatory support, and 6 (12\%) had cardiac dysautonomia. The median hospitalization time was 14 days (IQR 9-23 days).

One week after admission, the median mEGOS was 5 (IQR 2-9). Most patients improved as indicated by mRS score at 6-month follow-up (median 2, IQR 1-2) compared with nadir (median 4, IQR 4-5). Four patients (8\%) died. The most common sequela after 6 months was neuropathic pain (69\%) (table e-1, links.lww.com/NXI/A406).

\section{Laboratory Testing}

Hematologic and biochemical testing at admission were normal in all cases. CSF examination was performed in 48/49 patients at a median of 5 days (IQR 4-7 days) after start of neurologic symptoms. All patients had normal cell counts (median 0, IQR 0-1), and 14 (29\%) had an increased protein level (>52 mg/dL) (table 1$)$.

Laboratory results for infectious agents and antiganglioside profiles are described in table 2. One patient with known HIV infection was HIV positive. Twenty (41\%) patients underwent testing for ZIKV, 26 (53\%) for DENV, and 22 (45\%) for CHIKV, and all were negative. Nineteen patients (39\%) underwent testing by Film Array respiratory panel, and 5 (26\%) were positive for common respiratory viruses not known to be associated with GBS (table 2).

In 43 patients (88\%), biosamples were available for $C$ jejuni infection testing with either molecular or serologic assays or stool cultures (table e-2, links.lww.com/NXI/A407). In 23/ 42 (55\%) patients, anti-C jejuni IgM and/or IgA antibodies were found, of whom 9 also tested positive for Campylobacter $s p$ PCR in stool. In contrast, only 11/41 (27\%) controls had 
Table 1 Demographic and Clinical Characteristics of Patients With GBS

\begin{tabular}{|c|c|}
\hline Characteristics & $N=49$ \\
\hline Age, y & $\begin{array}{l}44 \\
(30-54)\end{array}$ \\
\hline Male sex & $28(57)$ \\
\hline $\begin{array}{l}\text { General symptoms before the } \\
\text { onset of the GBS (last } 6 \mathrm{wk} \text { ) }\end{array}$ & $32(65)$ \\
\hline Diarrhea $^{a}$ & $24(49)$ \\
\hline Upper respiratory symptoms ${ }^{a}$ & $13(27)$ \\
\hline Fever & $5(10)$ \\
\hline Headache & $3(6)$ \\
\hline Arthralgia & $4(8)$ \\
\hline None & $17(35)$ \\
\hline $\begin{array}{l}\text { Time from onset of infectious } \\
\text { symptoms to admission, } d^{b}\end{array}$ & $7(7-14)$ \\
\hline Time from onset of infectious symptoms to GBS onset, $d^{\text {b }}$ & $3(2-9)$ \\
\hline Time from onset of GBS symptoms to admission, $d$ & $4(3-6)$ \\
\hline Time from onset of GBS symptoms to nadir, $d$ & $6(3-7)$ \\
\hline GBS Disability Score at admission & $4(3-4)$ \\
\hline $\begin{array}{l}\text { Erasmus GBS Respiratory Insufficiency Score at } \\
\text { admission }\end{array}$ & $3(2-4)$ \\
\hline Admission to ICU & $13(27)$ \\
\hline Mechanical ventilation & $12(24)$ \\
\hline Autonomic dysfunction & $6(12)$ \\
\hline Duration of hospitalization, $d$ & $14(9-23)$ \\
\hline \multicolumn{2}{|l|}{ Brighton criteria for GBS diagnosis } \\
\hline Level 1 & $41(84)$ \\
\hline Level 2 & $8(16)$ \\
\hline \multicolumn{2}{|l|}{ GBS clinical variant } \\
\hline Pure motor & $39(80)$ \\
\hline Sensorimotor & $6(12)$ \\
\hline Pharyngeal-cervical-brachial & $2(4)$ \\
\hline Miller Fisher syndrome & $1(2)$ \\
\hline Bickerstaff brainstem encephalitis & $1(2)$ \\
\hline CSF analysis & $48(98)$ \\
\hline $\begin{array}{l}\text { Time from onset neurologic symptoms } \\
\text { to CSF sampling, d }\end{array}$ & $5(4-7)$ \\
\hline White cell count, cells $/ \mathrm{mm}^{3}$ & $0(0-1)$ \\
\hline Total protein, $\mathrm{mg} / \mathrm{dL}$ & $\begin{array}{l}33 \\
(16-58)\end{array}$ \\
\hline Increased protein level ${ }^{c}$ & $14(29)$ \\
\hline Time from GBS symptom onset to EMG, $d$ & $\begin{array}{l}16 \\
(10-23)\end{array}$ \\
\hline
\end{tabular}

Table 1 Demographic and Clinical Characteristics of Patients With GBS (continued)

\begin{tabular}{lc}
\hline Characteristics & $\mathbf{N}=\mathbf{4 9}$ \\
\hline NCS/EMG results and subtype & \\
\hline AMAN & $21(43)$ \\
\hline AIDP & $9(18)$ \\
\hline Inexcitable & $5(10)$ \\
\hline Equivocal & $8(16)$ \\
\hline Normal & $6(12)$ \\
\hline
\end{tabular}

Abbreviations: AIDP = acute inflammatory demyelinating polyneuropathy; AMAN = acute motor axonal neuropathy; GBS = Guillain-Barré syndrome; ICU = intensive care unit; NCS = nerve conduction study.

Data are presented as $\mathrm{n} / \mathrm{N}(\%)$ or median (interquartile range).

a Six patients had both diarrhea and upper respiratory symptoms.

${ }^{b}$ Based on 32 patients with a history of preceding general symptoms.

c Increased protein level is defined as $>52 \mathrm{mg} / \mathrm{dL}$. The percentage is based on 48 CSF samples.

evidence of anti-C jejuni IgM or IgA (OR: 3.3, CI 95\% 1.2-9.2, $p<0.01)($ table 2).

The PCR-based gastrointestinal panel showed that 14/37 (38\%) patients had evidence of Campylobacter sp genome. Stool cultures from 4 of these patients grew bacteria, which were confirmed as $C$ jejuni by immunologic and molecular assays (table 2, table e-2, links.lww.com/NXI/A407). Penner molecular typing indicated that these isolates were all HS41 capsule type. Genomic analysis showed that these strains were clonal, sequence type (ST) ST2993, with class A LOS biosynthesis locus, a pathogenicity island that contains genes with the potential to generate LOS that mimic human gangliosides. Phylogenetic analysis showed that of the 20 GBS-associated $C$ jejuni genomes, 15 , including the 4 isolates from this study, have LOS regions fairly closely related to one another and to other strains of $C$ jejuni associated with GBS isolated in China and Africa (figures 2 and 3). Sample collection regions do not appear to define clades, with strains from countries with numerous samples spread throughout the tree. All $4 \mathrm{C}$ jejuni isolates from our study had the Asn51 polymorphism at cstII gene (figure e-1, links.lww.com/NXI/A404) based on the alignments to ICDCCJ07001 indicating the capability to synthesize both alpha 2-3 and alpha 2-8 sialic acid linkages on their LOS core oligosaccharide. ${ }^{26,27}$ The genomes of these $4 \mathrm{C}$ jejuni isolates were deposited at NCBI within BioProject PRJNA643291 (accession numbers SAMN15508151, SAMN15508152, SAMN15508153, and SAMN15508154, ncbi.nlm.nih.gov/bioproject/PRJNA643291).

Combining serologic assay and stool PCR, 28/43 patients $(65 \%)$ had evidence of recent $C$ jejuni infection (table 2, table e-2, links.lww.com/NXI/A407). Of interest, these 28 patients did not significantly differ in the time to nadir, clinical variants, or electrophysiologic subtypes to the 15 patients without evidence of a recent $C$ jejuni infection (table e-2). Patients 
Table 2 Laboratory Studies

\begin{tabular}{|c|c|}
\hline \multicolumn{2}{|c|}{ A. Investigation of Infectious Agents in GBS Cases } \\
\hline Test/Target & n/N (\%) \\
\hline \multicolumn{2}{|l|}{ qRT-PCR (serum) } \\
\hline ZIKV & $0 / 20(0)$ \\
\hline DENV $^{a}$ & $0 / 26(0)$ \\
\hline CHIKV & $0 / 22(0)$ \\
\hline HIV (ELISA) & $1 / 49(2)$ \\
\hline \multicolumn{2}{|c|}{ Respiratory FilmArray (oropharyngeal swab) ${ }^{\mathbf{b}}$} \\
\hline Rhinovirus/enterovirus & $3 / 19(16)$ \\
\hline Respiratory syncytial virus & $1 / 19(5)$ \\
\hline Coronavirus OC43 & $1 / 19(5)$ \\
\hline 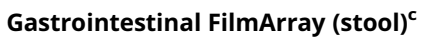 & $24 / 37(65)^{d}$ \\
\hline Campylobacter $s p^{e}$ & $14 / 37(38)$ \\
\hline Escherichia coli & $16 / 37(43)$ \\
\hline Stool culture & $11 / 37(30)^{f}$ \\
\hline Campylobacter jejuni HS41 & $4 / 37(11)$ \\
\hline E coli & $10 / 37(27)$ \\
\hline
\end{tabular}

\section{B. Serologic Case-Control Studies}

\begin{tabular}{|c|c|c|c|}
\hline & GBS, no. (\%) & Controls, no. (\%) & OR $(p)$ \\
\hline \multicolumn{4}{|l|}{ Campylobacter jejuni serology } \\
\hline Patients tested, no. (\%) & $42(100)$ & $41(100)$ & - \\
\hline Anti-C jejuni IgG & $42(100)$ & $41(100)$ & - \\
\hline Anti-C jejuni IgM or IgA & $23(55)$ & $11(27)$ & $3.3(0.01)$ \\
\hline Anti-C jejuni IgM & $19(45)$ & $11(27)$ & $2.3(0.081)$ \\
\hline Anti-C jejuni IgA & $12(29)$ & 0 & - \\
\hline \multicolumn{4}{|l|}{ Antiganglioside profile } \\
\hline Patients tested, no. (\%) & $42(100)$ & $41(100)$ & - \\
\hline GaINAc-GD1a-GBS cases & $3(7)$ & $4(10)$ & $0.7(0.668)$ \\
\hline GM1-GBS cases & $4(10)$ & $1(2)$ & $4.2(0.175)$ \\
\hline GM1:GT1a-GBS cases & $14(33)$ & $4(10)$ & $4.6(0.009)$ \\
\hline GM1:PS-GBS cases & $17(40)$ & $8(20)$ & $2.8(0.037)$ \\
\hline GT1a-GBS cases & $4(9)$ & $1(2)$ & $4.2(0.175)$ \\
\hline
\end{tabular}

Abbreviations: $\mathrm{CHIKV}=$ chikungunya virus; GBS = Guillain-Barré syndrome; $\mathrm{DENV}=$ dengue virus; $\mathrm{PS}$ = phosphatidylserine; qRT = quantitative real time; ZIKV = Zika virus . Bold values in OR $(p)$ column indicate statistical significance $(p<0.05)$.

${ }^{\text {a }}$ All samples were tested for DENV-1, DENV-2, DENV-3, and DENV-4.

$\mathrm{b}$ In addition to the listed pathogens detected by the respiratory array assay, other pathogens tested were found negative and those included Mycoplasma pneumoniae, adenovirus, coronavirus HKU1, NL63, 229E, and OC43, human metapneumovirus, influenza A, A/H1, A/H3, and A/H1-2009, influenza B, parainfluenza virus 1, 2, 3, and 4, Bordetella pertussis, and Chlamydia pneumoniae.

' In addition to the $C$ jejuni and $E$ coli detected, testing for other bacteria, parasite, and viruses included in the assay were negative, which included bacteria: Clostridium difficile (toxin A/B), Plesiomonas shigelloides, Salmonella, Yersinia enterocolitica, Vibrio (parahaemolyticus, vulnificus, and cholerae), Vibrio cholerae, diarrheagenic $E$ coli/Shigella, enteroaggregative $E$ coli (EAEC), enteropathogenic $E$ coli (EPEC), enterotoxigenic $E$ coli (ETEC), Shiga-like toxin-producing $E$ coli (STEC), E coli O157, and Shigella/enteroinvasive E coli (EIEC). Parasites: cryptosporidium, Cyclospora cayetanensis, Entamoeba histolytica, and Giardia lamblia. Viruses: adenovirus F 40/41, astrovirus, norovirus GI/GII, rotavirus A, and sapovirus (I, II, IV, and V).

${ }^{\mathrm{S}} \mathrm{Six}$ patients had coinfection of both Campylobacter sp and $E$ coli.

e Campylobacter (jejuni, coli, and upsaliensis).

${ }^{\mathrm{f}}$ Three patients had positive culture for both C jejuni HS41 and E coli. 


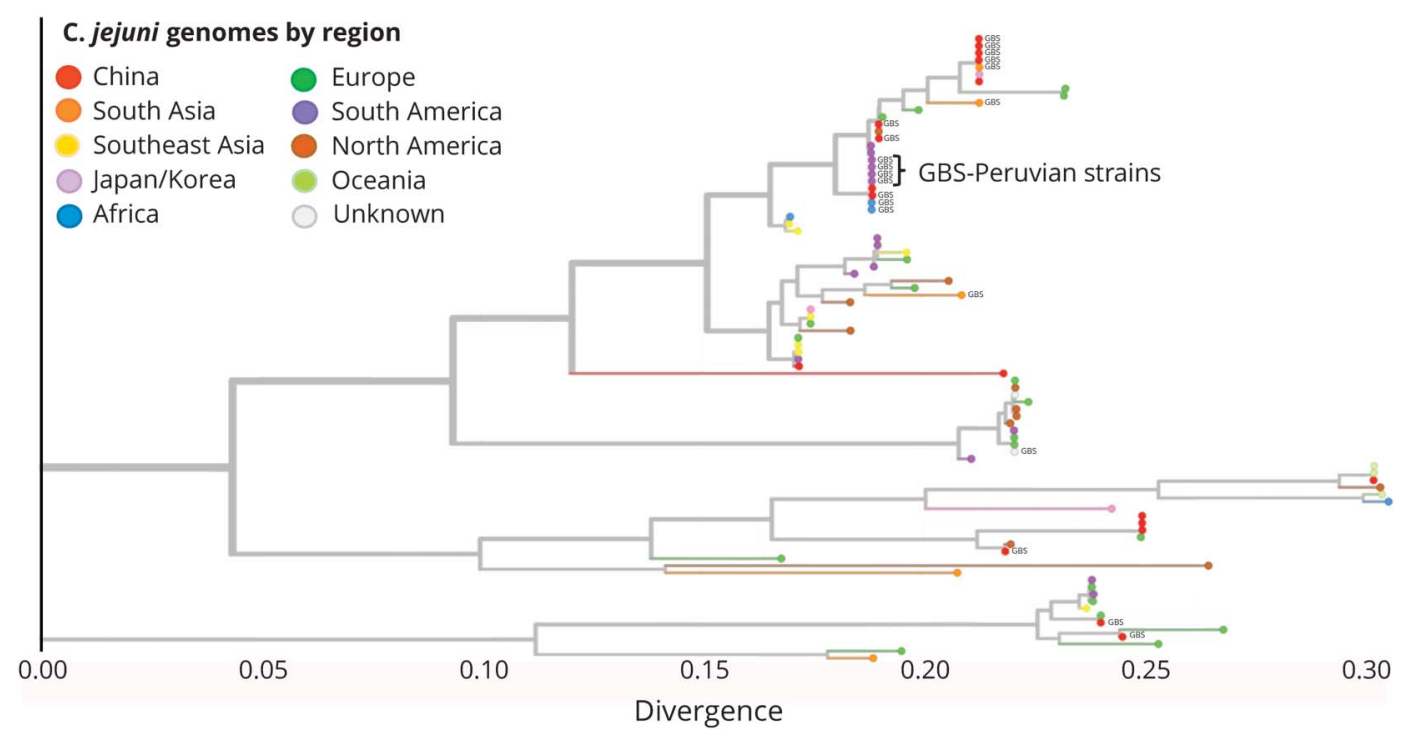

Phylogenetic tree built from the lipo-oligosaccharide region of $88 \mathrm{C}$ jejuni species using the Nextstrain pipeline, colored by region. The 4 Peruvian strain assemblies are indicated. The tree was built via alignment to the ICDCCJ07001 strain and then rooted by inferring ancestral states. GBS = Guillain-Barré syndrome.

with evidence of a recent $C$ jejuni infection had a higher percentage of preceding gastrointestinal symptoms, although this was not significant ( $43 \%$ vs $27 \%, p=0.69$ ). Other preceding infectious symptoms were also not significantly different.

Antiganglioside IgG antibodies of differing specificities were detected in a high proportion of cases compared with HCs (figure e-2, links.lww.com/NXI/A405). Summarizing this overview heatmap, 2 broad populations of IgG antibodies were dominantly present in this cohort: those reactive with GM1 alone or in complexes and those reactive with GT1a, alone or in complexes (table 2, figure 4). A smaller number of samples contained antibodies to GalNAc-GD1a alone or in complexes. Antibodies to other gangliosides including GM2, GD1b, GD1a, and GT1b and to myelin glycolipids including SGPG, LM1 and GalC were either very infrequently or not observed. Ganglioside antigens were probed as single

Figure 3 Phylogenetic Map of Campylobacter jejuni Isolates in Guillain-Barré Syndrome (GBS)

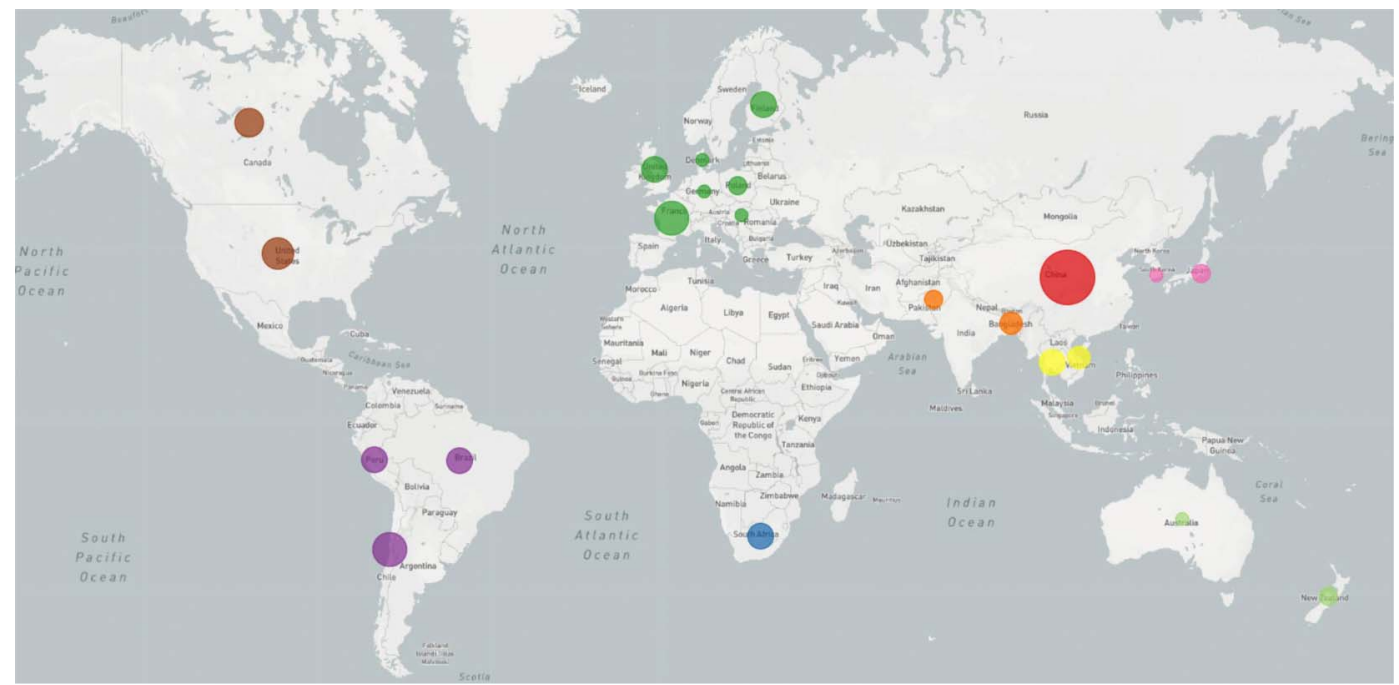

Map distribution of strains depicted in the phylogenetic tree. Strains are colored by region of collection, which was available for all but 2 genomes, the $C$ jejuni reference, NCTC11168, and 1 GBS-associated strain, G1, which had no listed collection location. The size of the circles within countries on the associated world map is proportional to how many samples are included from that country. 
molecules and when in heteromeric complex (1:1 ratio) with one other ganglioside or lipid. This use of complexes is known to enhance antiganglioside antibody signals in a proportion of serum samples. ${ }^{28}$ To identify the enhanced binding intensities resulting from complexes, samples were probed against GM1 and GT1a in complex with other lipids (figure 4A). Results were then analyzed and displayed using ROC curve analysis in which the true and false-positive rates are calculated at various threshold settings to generate sensitivity and specificity data for the assay. ROC data for the major targets are shown in figure 4, B and C and figure e-2B and C. Using this approach, GM1 ganglioside in a 1:1 heteromeric complex ratio with PS or GT1a ganglioside proved to be the most significant diagnostic marker. When GM1 was in complex with PS, antibodies to the GM1:PS complex returned a sensitivity $78.6 \%$ and a specificity of $78.0 \%$ for GBS (figure e-2B). When GM1 was in complex with GT1a, antibodies to the GM1:GT1a complex returned a sensitivity of $81.0 \%$ and a specificity of $80.5 \%$ for GBS (figure 4B). The enhancing effect, as manifested by an increase in fluorescence intensity units, of GM1 in complex with GTla vs either antigen alone is shown in figure 4C. In contrast, the GM1:GalNAc-GD1a complex did not enhance reactivity with either glycolipid alone (figure e-2C). When selecting the GM1:PS and GT1a:GM1 complex antigen targets as biomarkers of GBS, $92.9 \%$ of patients had IgG antibodies to one or both of these glycolipid complexes compared with $31.7 \%$ of HCs.

\section{Discussion}

In the aftermath of the ZIKV epidemic in Latin America, that was associated with significant increases in the incidence of GBS, 2 large seasonal outbreaks of GBS occurred in Peru in 2018 and 2019. ${ }^{6,29}$ Our study, describing a large cohort of patients and controls during the 2019 GBS outbreak in Lima, Peru, demonstrates that this outbreak was associated with $C$ jejuni infection, a diarrheal bacterium that is the most common trigger of GBS worldwide. As the outbreak of GBS in 2018 occurred in the same season and regions of the country (figure 1B), this outbreak was likely related to $C$ jejuni as well. Because stricter public health measures were instituted in Peru, after the first COVID-19 case in March 2020, GBS incidence decreased to less than $0.27 / 100,000{ }^{6}$

Figure 4 Antiganglioside Antibody Binding Profile in Peruvian GBS Cases

A

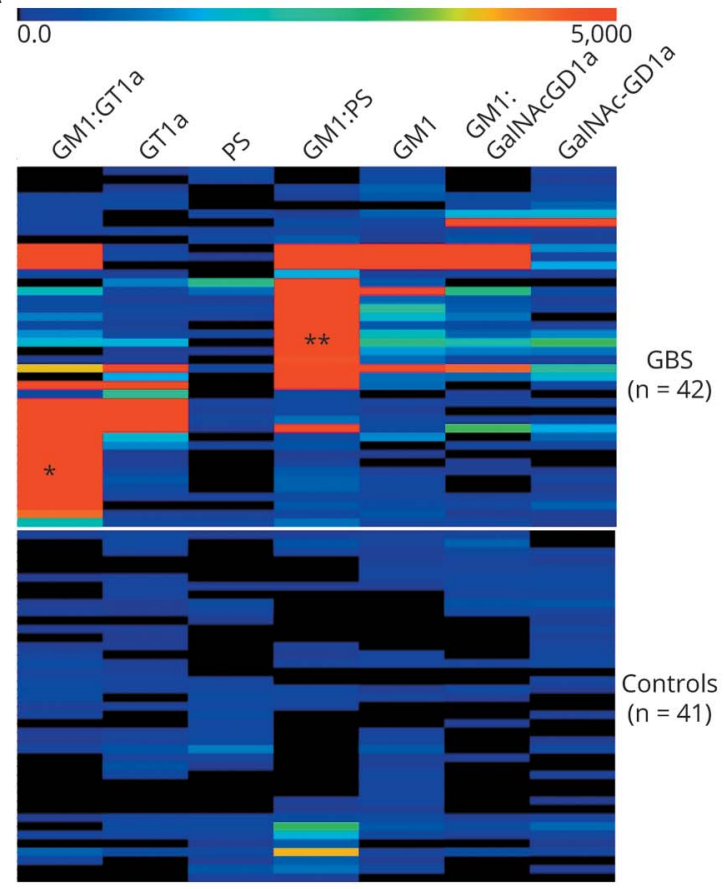

B

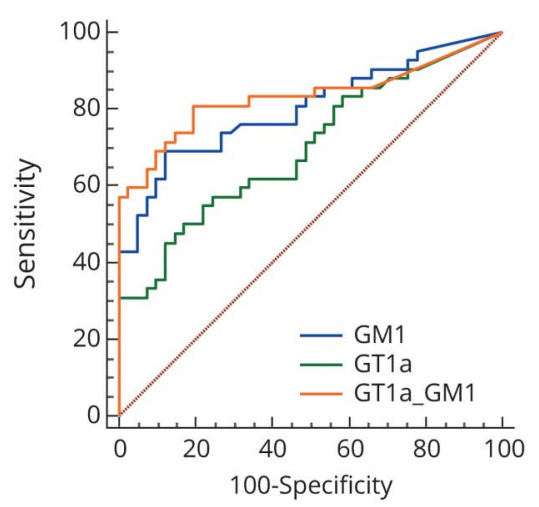

C

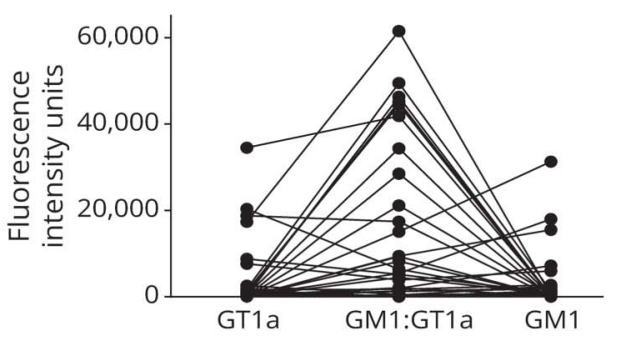

Graphical displays of GBS and healthy control $(\mathrm{HC})$ serum IgG antiganglioside antibody binding. (A) Heat maps illustrating the IgG binding intensity to 3 single glycolipids and 4 heteromeric complex antigen targets in GBS cases (upper map, $n=42$ ) and HC sera (lower map, $n=41$ ). Each horizontal row refers to the IgG binding reactivity of an individual GBS or HC serum sample, and each vertical row refers to each of the 7 targets displayed. The rainbow bar denotes the intensity scale of IgG binding from low (blue) to high (red) intensity. Two patterns of reactivity are greatly amplified by presenting glycolipids/lipids targets as heteromeric complexes compared with binding to each target alone: GM1:GT1a complex (first column *) and GM1:PS complex (fourth column **). Note that these 2 patterns of heteromeric complex reactivity do not substantially overlap within any 1 patient, being mutually exclusive. (B) An illustrative receiver operating characteristic (ROC) curve comparing the sensitivity and specificity of GT1a and GM1 as single glycolipids with the GT1a:GM1 heteromeric complex. The highest sensitivity (81\%) and specificity (80.5\%) are seen with the GM1:GT1a complex. (C) IgG reactivity values of each individual patient are plotted for the same 3 antigen targets (GM1, GT1a, and GM1:GT1a complex) subjected to ROC analysis in panel B. Greatly enhanced binding intensity to the GT1a:GM1 heteromeric complex compared with the sum of the single glycolipid antigens is present in most samples. GBS = Guillain-Barre syndrome; PS = phosphatidylserine. 
We found evidence of recent $C$ jejuni infection in 28/43 patients (65\%), of whom 9 were positive for Campylobacter $s p$ $\mathrm{PCR}$ in stool. Other preceding infections previously associated with GBS, including Mycoplasma pneumoniae, DENV, CHIKV, and $\mathrm{ZIKV}$, were negative in all tested cases. Recent $C$ jejuni infection was significantly more likely to occur in GBS cases (23/42, 55\%) compared with controls (11/41, 27\%, OR: $3.3, p$ $<0.01)$. Of interest, the proportion of controls with a recent $C$ jejuni infection was high (27\%), which may be indicative of an ongoing outbreak of $C$ jejuni, although our study was not designed to investigate this. This high percentage may also be in part due to overmatching of cases and controls or a high prevalence of $C$ jejuni in Peru, as has been indicated by previous serosurveillance studies. ${ }^{30,31}$ Notably, the vast majority of $C$ jejuni infections, even when bearing ganglioside mimics in their LOS, manifest as uncomplicated enteritis and are not associated with the development of GBS. Genomic analysis of $C$ jejuni isolates showed that they have closely related LOS regions to one another and to previously described GBSassociated $C$ jejuni genomes from China and Africa reported in the past 2 decades, suggesting that these strains were introduced or reemergent infections from an endemic reservoir rather than being new emergent strains. ${ }^{32-34}$

Besides the laboratory evidence, the clinical and electrophysiologic profile is typical for $C$ jejuni-associated GBS as described in previous studies. ${ }^{9,35,36}$ The majority of cases had a preceding diarrheal illness, followed by an early-onset, rapidly progressive pure motor axonal GBS. This profile is in contrast to the clinical profile that has been reported in association with ZIKV or COVID-19, where most patients have facial palsy, sensory and motor deficits, and a demyelinating electrophysiologic subtype. ${ }^{37,38}$

However, there was not a uniform relationship between $C$ jejuni serotype and clinical, electrodiagnostic, and antiganglioside profile. This may be due to methodological factors that prevent unambiguous case definition and ascertainment. For example, CSF examination and electrodiagnostic studies are not always sensitive diagnostic tools in GBS, especially when done early in the disease course. This may have resulted in only $29 \%$ of patients having an increased protein level in CSF, or inaccurate classification of electrophysiologic studies as axonal or demyelinating. ${ }^{8,39}$ The time between onset of systemic and neurologic symptoms (median 3 days, IQR 2-9 days) was also shorter than expected based on previous studies, which may be due to the wide range of the incubation period of $C$ jejuni (1-10 days); patients only reporting symptoms when they become severe; or the presence of a parainfectious rather than postinfectious mechanism, as previously reported in ZIKV-related GBS. ${ }^{3,40}$ Another surprising finding was the high percentage (27\%) of cases with diarrhea in the group without evidence of a recent $C$ jejuni infection. This may due to the presence of other infections able to trigger GBS that may lead to gastrointestinal symptoms or low sensitivity of the standard serologic testing method for recent $C$ jejuni infection (presence of IgM antibody) in a population where the incidence of infection, as indicated by the universally positive IgG serology, is very high. Notwithstanding previous studies that show diarrhea has been associated with a poor prognosis, the percentage of our patients able to walk at 6 months was high (82\%), although we did find that diarrhea was more frequent $(67 \%$ vs $45 \%)$ in patients with worse outcome, as defined by $\mathrm{mRS}$ score $\geq 4$ at 6 months. ${ }^{35,41}$

The antiganglioside antibody profile, with strong positivity for GM1 and anti-GT1a, as single antigens or in complex, is similar to what has previously been found in post-C jejuni GBS in other parts of the world and lends strong support that these patients represent the typical immune phenotype seen in C jejuni-associated GBS. ${ }^{42-44}$ The use of complexes of GM1 and GT1a with each other or other lipids (herein PS) greatly enhanced the sensitivity of antibody detection in this cohort. The significant presence and high frequency of antiganglioside antibodies lends strong evidence to the conclusion that molecular mimicry between Campylobacter LOS and gangliosides is the immunopathologic driver of this form of GBS in Peru. The high prevalence of anti-GT1a antibodies in this groups is consistent with the cstII polymorphism (Asn51) seen in this study and similar to that observed in a GBS outbreak in China. ${ }^{45}$

The main limitation of our study is that we were not able to perform complete laboratory studies in all patients and controls as the study was conducted in the context of an emerging outbreak. We were able to exclude other preceding infections, including arboviruses, in 53\% of cases and completed the serologic case-control study in $86 \%$ of cases. It is unlikely that different results would have been obtained had all subjects been tested.

In conclusion, we showed that $C$ jejuni, and not ZIKV as was initially thought, was the infectious driver of the 2019 GBS outbreak in Peru, and the clinical, electrophysiologic, and immunologic profile was consistent with $C$ jejuni-related GBS. The $C$ jejuni strains were likely introduced or reemergent infections from an endemic reservoir and not new emergent strains. This finding has global relevance as it indicates that the $C$ jejuni strains linked to GBS circulate widely in different parts of the world. This shows that researchers should remain aware of $C$ jejuni as a trigger for GBS when investigating the association between other infections, including COVID-19, and GBS. Reinforcing public health measures, including setting up campylobacteriosis and GBS surveillance, to rapidly identify new epidemics, pathologic strains, and sources of transmission should be encouraged to prevent future outbreaks. $30,31,46$

\section{Acknowledgment}

The authors are grateful to Drs. Aida Palacios and Wilde Lavado for their continuous support during the Peruvian GBS outbreak in Hospital Cayetano Heredia; Maria Bernal and Enrique Canal for their technical assistance in laboratory; and Dr. Kiran Thakur for their support for the project. 


\section{Study Funding}

Laboratory and research studies were funded in part by Global Emerging Infections Surveillance (M. Grogl); ZikaPLAN, European Union's Horizon 2020 research and innovation programme under Grant Agreement No. 734584 (B.C. Jacobs, H.J. Willison), and the Wellcome Trust, Grants 092805 and 202789 (H.J. Willison) and NIH R01 NS110122 (C.A. Pardo). The funding resources did not have any role in the writing of the manuscript or the decision to submit for publication.

\section{Disclosure}

A.P. Ramos, S.E. Leonhard, S.K. Halstead, M.A. Cuba, C.C. Castañeda, J.A. Dioses, M.A. Tipismana, J.T. Abanto, A. Llanos, and $\mathrm{D}$. Gourlay report no disclosure relevant to the manuscript. M. Grogl, M. Ramos, J.D. Rojas, and R. Meza are employees of the US Government. This work was prepared as part of our official duties. Title 17, U.S.C., $\$ 105$ provides that copyright protection under this title is not available for any work of the US Government. Title 17, U.S.C., $\$ 101$ defines a US Government work as a work prepared by a military service member or employee of the US Government as part of that persons official duties. The views expressed in this article reflect the results of research conducted by the authors and do not necessarily reflect the official policy or position of the Department of the Navy, Department of Defense, or the US Government. D. Puiu, R.M. Sherman, S.L. Salzberg, P.J. Simner, and H.J. Willison report no disclosure relevant to the manuscript. B.C. Jacobs receives unrestricted funding for research from Prinses Beatrix Spierfonds, GBS-CIDP Foundation International, CSL Behring, Grifols, Annexon, and Hansa Biopharma. D.R. Cornblath has received consultancy honoraria from Mitsubishi Tanabe Pharma Corporation, Alnylam Pharmaceuticals, Inc., Hansa Medical Ab, Pledpharma, Momenta Pharmaceuticals, Inc., CSL Behring, Sanofi Aventis Recherche \& Developpement, Pfizer Inc., Seattle Genetics Inc., Octapharma Ag, Grifols, S.A., Cigna Corporation, Pharnext SA, Annexon Biosciences, UCB Pharma Inc., Boehringer Ingelheim, Biotest Pharmaceuticals, Inc., Argenx, Cytomx Therapeutics, Passage Bio Pharma, Seattle Genetics Inc., Astra Zeneca Pharmaceuticals Lp, Genentech Corp, Merrimack Pharmaceuticals, Disarm Therapeutics, Inc., Levicept Ltd., and Amgen Inc. Johns Hopkins University has the rights to The Total Neuropathy Score $@$ for which D.R. Cornblath receives royalty payments. H.F. Umeres and C.A. Pardo report no disclosure relevant to the manuscript. Go to Neurology.org/NN for full disclosures.

\section{Publication History}

Received by Neurology: Neuroimmunology \& Neuroinflammation July 17, 2020. Accepted in final form November 23, 2020.

\section{Appendix Authors}

\begin{tabular}{lll}
\hline Name & Location & Contribution \\
\hline $\begin{array}{ll}\text { Ana P. } \\
\text { Ramos, MD }\end{array}$ & $\begin{array}{l}\text { Hospital Cayetano } \\
\text { Heredia, Lima, Perú }\end{array}$ & $\begin{array}{l}\text { Designed and conceptualized } \\
\text { the study; acquired, analyzed, } \\
\text { and interpreted the overall data; } \\
\text { and drafted the manuscript for } \\
\text { intellectual content }\end{array}$ \\
\hline
\end{tabular}

Appendix (continued)

\begin{tabular}{lll}
\hline Name & Location & Contribution \\
\hline $\begin{array}{l}\text { Sonja E. } \\
\text { Leonhard, }\end{array}$ & $\begin{array}{l}\text { Erasmus MC, University } \\
\text { MD }\end{array}$ & $\begin{array}{l}\text { Analyzed C jejuni serology, } \\
\text { analyzed and interpreted } \\
\text { Rotterdam, Netherlands } \\
\text { data, and drafted the } \\
\text { manuscript for intellectual } \\
\text { content }\end{array}$ \\
\hline
\end{tabular}

\begin{tabular}{lll}
\hline $\begin{array}{l}\text { Susan K. } \\
\text { Halstead, } \\
\text { PhD }\end{array}$ & $\begin{array}{l}\text { University of Glasgow, } \\
\text { Glasgow, United } \\
\text { Kingdom }\end{array}$ & $\begin{array}{l}\text { Performed antiganglioside } \\
\text { antibody analysis and revised } \\
\text { the manuscript for } \\
\text { intellectual content }\end{array}$ \\
\hline $\begin{array}{l}\text { Mireya A. } \\
\text { Cuba, MD }\end{array}$ & $\begin{array}{l}\text { Hospital Cayetano } \\
\text { Heredia, Lima, Perú }\end{array}$ & $\begin{array}{l}\text { Acquired clinical data and } \\
\text { revised the manuscript for } \\
\text { intellectual content }\end{array}$ \\
\hline $\begin{array}{l}\text { Carlos C. } \\
\text { Castañeda, } \\
\text { MD }\end{array}$ & $\begin{array}{l}\text { Hospital Cayetano } \\
\text { Heredia, Lima, Perú }\end{array}$ & $\begin{array}{l}\text { Acquired and analyzed } \\
\text { electrophysiology } \\
\text { data and revised the } \\
\text { manuscript for } \\
\text { intellectual content }\end{array}$ \\
& & $\begin{array}{l}\text { Acquired and analyzed } \\
\text { electrophysiology } \\
\text { data and revised the } \\
\text { manuscript for intellectual } \\
\text { content }\end{array}$ \\
Dioses, MD & Hospital Cayetano &
\end{tabular}

\begin{tabular}{lll}
\hline $\begin{array}{l}\text { Martin A. } \\
\text { Tipismana, } \\
\text { MD }\end{array}$ & $\begin{array}{l}\text { Hospital Cayetano } \\
\text { Heredia, Lima, Perú }\end{array}$ & $\begin{array}{l}\text { Acquired clinical data and } \\
\text { revised the manuscript for } \\
\text { intellectual content }\end{array}$ \\
\hline $\begin{array}{l}\text { Jesus T. } \\
\text { Abanto, MD }\end{array}$ & $\begin{array}{l}\text { Hospital Cayetano } \\
\text { Heredia, Lima, Perú }\end{array}$ & $\begin{array}{l}\text { Analyzed laboratory } \\
\text { data and revised the } \\
\text { manuscript for } \\
\text { intellectual content }\end{array}$ \\
\hline
\end{tabular}

\begin{tabular}{lll}
\hline $\begin{array}{l}\text { Alejandro } \\
\text { Llanos, MD, } \\
\text { PhD }\end{array}$ & $\begin{array}{l}\text { Hospital Cayetano } \\
\text { Heredia, Lima, Perú }\end{array}$ & $\begin{array}{l}\text { Analyzed laboratory data and } \\
\text { revised the manuscript for } \\
\text { intellectual content }\end{array}$ \\
\hline $\begin{array}{l}\text { Dawn } \\
\text { Gourlay, } \\
\text { BSc, MSc }\end{array}$ & $\begin{array}{l}\text { University of Glasgow, } \\
\text { United Kingdom }\end{array}$ & $\begin{array}{l}\text { Performed antiganglioside } \\
\text { antibody analysis and revised } \\
\text { the manuscript for } \\
\text { intellectual content }\end{array}$ \\
\hline
\end{tabular}

\begin{tabular}{lll}
\hline $\begin{array}{l}\text { Max Grogl, } \\
\text { PhD }\end{array}$ & $\begin{array}{l}\text { U.S. Naval Medical } \\
\text { Research Unit-6, Lima, } \\
\text { Peru }\end{array}$ & $\begin{array}{l}\text { Interpreted bacteriology and } \\
\text { virology data and revised the } \\
\text { manuscript for intellectual } \\
\text { content }\end{array}$ \\
\hline $\begin{array}{l}\text { Mariana } \\
\text { Ramos, MD }\end{array}$ & $\begin{array}{l}\text { U.S. Naval Medical } \\
\text { Pesearch Unit-6, Lima, }\end{array}$ & $\begin{array}{l}\text { Conducted field work during } \\
\text { outbreak response, analyzed } \\
\text { bacteriology and virology } \\
\text { data, and revised the } \\
\text { manuscript for intellectual } \\
\text { content }\end{array}$ \\
\end{tabular}

Jesus D. U.S. Naval Medical Performed and analyzed

Rojas, BSc Research Unit-6, Lima, bacteriology and virology Peru data and revised the manuscript for intellectual content

\begin{tabular}{lll}
\hline Rina Meza, & U.S. Naval Medical & $\begin{array}{l}\text { Conducted field work } \\
\text { BSc }\end{array}$ \\
& Research Unit-6, Lima, & during outbreak \\
& response, performed and \\
& analyzed bacteriology \\
& and virology data, and \\
& revised the manuscript \\
& for intellectual \\
& content
\end{tabular}

\begin{tabular}{lll}
\hline Daniela & Johns Hopkins University, & Analyzed C jejuni genomic \\
Puiu, MS & Baltimore, MD & $\begin{array}{l}\text { studies and revised the } \\
\text { manuscript for intellectual } \\
\text { content }\end{array}$
\end{tabular}


Appendix (continued)

\begin{tabular}{lll}
\hline Name & Location & Contribution \\
\hline $\begin{array}{l}\text { Rachel M. } \\
\text { Sherman, } \\
\text { BS, MSE }\end{array}$ & $\begin{array}{l}\text { Johns Hopkins University, } \\
\text { Baltimore, MD }\end{array}$ & $\begin{array}{l}\text { Analyzed C jejuni genomic } \\
\text { studies and revised the } \\
\text { manuscript for intellectual } \\
\text { content }\end{array}$ \\
\hline $\begin{array}{l}\text { Steven L. } \\
\text { Salzberg, } \\
\text { PhD }\end{array}$ & Johns Hopkins University, & $\begin{array}{l}\text { Analyzed C jejuni genomic } \\
\text { studies and revised the } \\
\text { manuscript for intellectual } \\
\text { content }\end{array}$ \\
\hline
\end{tabular}

Patricia J. Johns Hopkins University , Recultured C jejuni isolates, Simner, Baltimore, MD performed DNA sequencing PhD and revised the manuscript for intellectual content

\begin{tabular}{lll}
\hline Hugh J. & University of Glasgow, & $\begin{array}{l}\text { Performed antiganglioside } \\
\text { Willison, }\end{array}$ \\
MBBS & United Kingdom & $\begin{array}{l}\text { and interpretys data, and } \\
\text { drafted the manuscript for } \\
\text { intellectual content }\end{array}$
\end{tabular}

Bart C. Erasmus MC, University Performed and analyzed $C$
Jacobs, MD Medical Center jejuni serology and revised Rotterdam, Netherlands the manuscript for intellectual content

\begin{tabular}{lll}
\hline $\begin{array}{l}\text { David R. } \\
\text { Cornblath, }\end{array}$ & $\begin{array}{l}\text { Johns Hopkins University, } \\
\text { MD }\end{array}$ & $\begin{array}{l}\text { Analyzed electrophysiology } \\
\text { data and revised the } \\
\text { manuscript for intellectual } \\
\text { content }\end{array}$ \\
\hline
\end{tabular}

\begin{tabular}{lll}
\hline Hugo F. & Hospital Cayetano & $\begin{array}{l}\text { Supervised the study and } \\
\text { revised the manuscript for } \\
\text { Umeres, }\end{array}$ \\
MD & Heredia, Lima, Perú &
\end{tabular}

Carlos A. Johns Hopkins University, Analyzed and interpreted Pardo, MD Baltimore, MD overall data, analyzed $C$ jejuni genomic studies, and drafted the manuscript for intellectual content

\section{References}

1. Willison HJ, Jacobs BC, Van Doorn PA. Guillain-Barré syndrome. Lancet 2016;388: 717-727.

2. WHO. Guillain-Barré syndrome. Available at: who.int/csr/don/archive/disease/ guillain-barre-syndrome/en/. Accessed May 31, 2020.

3. Parra B, Lizarazo J, Jiménez-Arango JA, et al. Guillain-Barré syndrome associated with Zika virus infection in Colombia. N Engl J Med 2016;375:1513-1523.

4. Styczynski AR, Malta JMAS, Krow-Lucal ER, et al. Increased rates of Guillain-Barré syndrome associated with Zika virus outbreak in the Salvador metropolitan area, Brazil. PLoS Negl Trop Dis 2017;11:1-13.

5. Gigli GL, Bax F, Marini A, et al. Guillain-Barré syndrome in the COVID-19 era: just an occasional cluster? J Neurol 2020;1:3. Letter.

6. Centro Nacional de Epidemiología Prevención y Control de Enfermedades. Situación de Guillain Barre: Perú a la SE 02_2020. Available at: dge.gob.pe/portal/index.php? option $=$ com content\&view=article\&id=654. Accessed July 4, 2020.

7. Centro Nacional de Epidemiología, Prevención y Control de Enfermedades. Reporte de Análisis del comportamiento epidemiológico. Available at: dge.gob.pe/salasituacional/sala/index/SALA VIGILA/141. Accessed November 3, 2020.

8. Sejvar JJ, Kohl KS, Gidudu J, et al. Guillain-Barré syndrome and Fisher syndrome: case definitions and guidelines for collection, analysis, and presentation of immunization safety data. Vaccine 2011;29:599-612.

9. Hadden RDM, Cornblath DR, Hughes RAC, et al. Electrophysiological classification of Guillain-Barre syndrome: clinical associations and outcome. Ann Neurol 1998;44:780-788.

10. Ho TW, Mishu B, Li CY, et al. Guillain-barré syndrome in Northern China relationship to Campylobacter jejuni infection and anti-glycolipid antibodies. Brain 1995; 118:597-605.

11. Jacobs BC, van den Berg B, Verboon C, et al. International Guillain-Barré syndrome outcome study: protocol of a prospective observational cohort study on clinical and biological predictors of disease course and outcome in Guillain-Barré syndrome. J Peripher Nerv Syst 2017;22:68-76.

12. Kleyweg RP, van der Meché FGA, Schmitz PIM. Interobserver agreement in the assessment of muscle strength Guillain-Barre syndrome. Muscle Nerv 1991;14: 1103-1109.
13. Van Swieten JC, Koudstaal PJ, Visser MC, Schouten H, Van Gijn J. Interobserver agreement for the assessment of handicap in stroke patients. Stroke 1988;19:604-607.

14. Hughes RAC, Newsom-Davis JM, Perkin GD, Pierce JM. Controlled trial of prednisolone in acute polyneuropathy. Lancet 1978;312:750-753.

15. Walgaard C, Lingsma HF, Ruts L, Van Doorn PA, Steyerberg EW, Jacobs BC. Early recognition of poor prognosis in Guillain-Barré syndrome. Neurology 2011;76: 968-975.

16. Walgaard C, Lingsma HF, Ruts L, et al. Prediction of respiratory insufficiency in Guillain-Barré syndrome. Ann Neurol 2010;67:781-787.

17. Sadon N, Delers A, Jarman RG, et al. A new quantitative RT-PCR method for sensitive detection of dengue virus in serum samples. J Virol Methods 2008;153: $1-6$.

18. Guion CE, Ochoa TJ, Walker CM, Barletta F, Cleary TG. Detection of diarrheagenic Escherichia coli by use of melting-curve analysis and real-time multiplex PCR. J Clin Microbiol 2008;46:1752-1757.

19. Klena JD, Parker CT, Knibb K, et al. Differentiation of Campylobacter coli, Campylobacter jejuni, Campylobacter lari, and Campylobacter upsaliensis by a multiplex PCR developed from the nucleotide sequence of the lipid A gene lpxA. J Clin Microbiol 2004;42:5549-5557.

20. Poly F, Serichantalergs O, Kuroiwa J, et al. Updated Campylobacter jejuni capsule PCR multiplex typing system and its application to clinical isolates from south and southeast Asia. PLoS One 2015;10:1-17.

21. Parkhill J, Wren BW, Mungall K, et al. The genome sequence of the food-borne pathogen Campylobacter jejuni reveals hypervariable sequences. Nature 2000;403: 665-668.

22. Gundogdu O, Bentley SD, Holden MT, Parkhill J, Dorrell N, Wren BW. Reannotation and re-analysis of the Campylobacter jejuni NCTC11168 genome sequence. BMC Genomics 2007;8:1-8.

23. Hadfield J, Megill C, Bell SM, et al. NextStrain: real-time tracking of pathogen evolution. Bioinformatics 2018;34:4121-4123.

24. Ang CW, Krogfelt K, Herbrink P, et al. Validation of an ELISA for the diagnosis of recent Campylobacter infections in Guillain-Barré and reactive arthritis patients. Clin Microbiol Infect 2007;13:915-922.

25. Halstead SK, Kalna G, Islam MB, et al. Microarray screening of Guillain-Barré syndrome sera for antibodies to glycolipid complexes. Neurol Neuroimmunol Neuroinflamm 2016;3:e284. doi: 10.1212/NXI.0000000000000284.

26. Gilbert M, Karwaski MF, Bernatchez S, et al. The genetic bases for the variation in the lipo-oligosaccharide of the mucosal pathogen, Campylobacter jejuni. Biosynthesis of sialylated ganglioside mimics in the core oligosaccharide. J Biol Chem 2002;277: 327-337.

27. Godschalk PCR, Heikema AP, Gilbert M, et al. The crucial role of Campylobacter jejuni genes in anti-ganglioside antibody induction in Guillain-Barré syndrome. J Clin Invest 2004;114:1659-1665.

28. Rinaldi S, Brennan KM, Kalna G, et al. Antibodies to heteromeric glycolipid complexes in Guillain-Barré syndrome. PLoS One 2013;8:1-13.

29. Díaz-Soto S, Chavez K, Chaca A, Alanya J, Tirado-Hurtado I. Outbreak of GuillainBarre syndrome in Peru. eNeurologicalSci 2019;14:89-90. Letter.

30. Fernández H. Campylobacter y campylobacteriosis: una mirada desde América del Sur. Rev Peru Med Exp Salud Publica 2011;28:121-148.

31. Kaakoush NO, Castaño-Rodríguez N, Mitchell HM, Man SM. Global epidemiology of campylobacter infection. Clin Microbiol Rev 2015;28:687-720.

32. Zhang M, Li Q, He L, et al. Association study between an outbreak of Guillain-Barre syndrome in Jilin, China, and preceding Campylobacter jejuni infection. Foodborne Pathog Dis 2010;7:913-919.

33. Prendergast MM, Lastovica AJ, Moran AP. Lipopolysaccharides from Campylobacter jejuni $\mathrm{O}: 41$ strains associated with Guillain-Barre syndrome exhibit mimicry of GM1 ganglioside. Infect Immun 1998;66:3649-3755.

34. Nachamkin I, Liu J, Li M, et al. Campylobacter jejuni from patients with Guillain-Barré syndrome preferentially expresses a GDla-like epitope. Infect Immun 2002;70: 5299-5303.

35. Rees JH, Soudain SE, Gregson NA, Hughes R. Campylobacter jejuni infection and Guillain-Barré syndrome. N Engl J Med 1995;333:1374-1379.

36. Ye Y, Zhu D, Wang K, et al. Clinical and electrophysiological features of the 2007 Guillain-Barré syndrome epidemic in northeast China. Muscle Nerve 2010;42: 311-314.

37. Leonhard SE, Bresani-Salvi CC, Lyra Batista JD, et al. Guillain-Barré syndrome related to Zika virus infection: a systematic review and meta-analysis of the clinical and electrophysiological phenotype. PLoS Negl Trop Dis 2020;14:1-24.

38. Dalakas MC. Guillain-Barré syndrome: the first documented COVID-19triggered autoimmune neurologic disease: more to come with myositis in the offing. Neurol Neuroimmunol Neuroinflammation 2020;7:e781. doi: 10.1212/ NXI.0000000000000781.

39. Uncini A, Ippoliti L, Shahrizaila N, Sekiguchi Y, Kuwabara S. Optimizing the electrodiagnostic accuracy in Guillain-Barré syndrome subtypes: criteria sets and sparse linear discriminant analysis. Clin Neurophysiol 2017;128:1176-1183.

40. WHO. Campylobacter. Available at: who.int/news-room/fact-sheets/detail/campylobacter. Accessed June 8, 2020.

41. Hadden RDM, Karch H, Hartung HP, et al. Preceding infections, immune factors, and outcome in Guillain-Barré syndrome. Neurology 2001;56:758-765.

42. Ogawa G, Kaida KI, Kuwahara M, Kimura F, Kamakura K, Kusunoki S. An antibody to the GM1/GalNAc-GD1a complex correlates with development of pure motor Guillain-Barré syndrome with reversible conduction failure. J Neuroimmunol 2013; 254:141-145. 
43. Ogawara K, Kuwabara S, Mori M, Hattori T, Koga M, Yuki N. Axonal Guillain-Barré syndrome: relation to anti-ganglioside antibodies and Campylobacter jejuni infection in Japan. Ann Neurol 2000;48:624-631.

44. Sekiguchi $\mathrm{Y}$, Uncini A, Yuki N, et al. Antiganglioside antibodies are associated with axonal Guillain-Barré syndrome: a Japanese-Italian collaborative study. J Neurol Neurosurg Psychiatry 2012;83:23-28.
45. Zhang M, Gilbert M, Yuki N, et al. Association of anti-GT1a antibodies with an outbreak of Guillain-Barré syndrome and analysis of ganglioside mimicry in an associated Campylobacter jejuni strain. PLoS One 2015;10:1-13.

46. Leonhard SE, Cornblath DR, Endtz HP, Sejvar JJ, Jacobs BC. Guillain-Barré syndrome in times of pandemics. J Neurol Neurosurg Psychiatry 2020;91: 1027-1029. 


\section{Neurology \\ Neuroimmunology \& Neuroinflammation}

\section{Guillain-Barré Syndrome Outbreak in Peru 2019 Associated With Campylobacter jejuni Infection \\ Ana P. Ramos, Sonja E. Leonhard, Susan K. Halstead, et al. \\ Neurol Neuroimmunol Neuroinflamm 2021;8; \\ DOI 10.1212/NXI.0000000000000952}

This information is current as of February 5, 2021

Updated Information \&

Services

References

Subspecialty Collections

Permissions \& Licensing

Reprints including high resolution figures, can be found at:

http://nn.neurology.org/content/8/2/e952.full.html

This article cites 42 articles, 9 of which you can access for free at: http://nn.neurology.org/content/8/2/e952.full.html\#\#ref-list-1

This article, along with others on similar topics, appears in the following collection(s):

Bacterial infections

http://nn.neurology.org//cgi/collection/bacterial_infections

Guillain-Barre syndrome

http://nn.neurology.org//cgi/collection/guillainbarre_syndrome

Public health

http://nn.neurology.org//cgi/collection/public_health

Information about reproducing this article in parts (figures,tables) or in its entirety can be found online at:

http://nn.neurology.org/misc/about.xhtml\#permissions

Information about ordering reprints can be found online:

http://nn.neurology.org/misc/addir.xhtml\#reprintsus

Neurol Neuroimmunol Neuroinflamm is an official journal of the American Academy of Neurology.

Published since April 2014, it is an open-access, online-only, continuous publication journal. Copyright

Copyright (C) 2021 The Author(s). Published by Wolters Kluwer Health, Inc. on behalf of the American

Academy of Neurology.. All rights reserved. Online ISSN: 2332-7812.

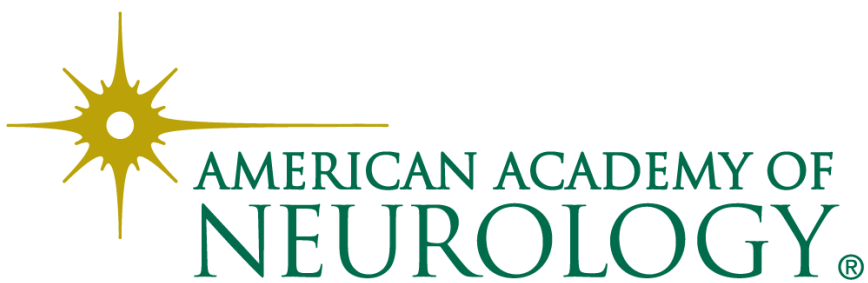

